\title{
Acoustic Emission and Ultrasonic Characteristics in the Failure Process of Cemented Waste Concrete-Coal Gangue Backfilling (CWCGB) under Uniaxial Loading
}

\author{
Guorui Feng $\mathbb{D}^{1,2}$ Tingye $Q i \mathbb{D}^{1,2,3}$ Xianjie Du, ${ }^{1}$ Zehua Wang $\mathbb{D}^{1},{ }^{1}$ and Yujiang Zhang $\mathbb{C}^{1}$ \\ ${ }^{1}$ College of Mining Engineering, Taiyuan University of Technology, Taiyuan, China \\ ${ }^{2}$ Shanxi Province Research Center of Green Mining Engineering Technology, Taiyuan, China \\ ${ }^{3}$ State Key Laboratory of Coal Resources and Safe Mining, China University of Mining and Technology, Xuzhou, China
}

Correspondence should be addressed to Tingye Qi; qty198402@163.com

Received 20 July 2018; Revised 20 September 2018; Accepted 27 September 2018; Published 11 December 2018

Academic Editor: Lukasz Sadowski

Copyright (c) 2018 Guorui Feng et al. This is an open access article distributed under the Creative Commons Attribution License, which permits unrestricted use, distribution, and reproduction in any medium, provided the original work is properly cited.

The acoustic emission (AE) characteristics, change law of the ultrasonic velocity, and internal failure mode of cemented waste concrete-coal gangue backfilling (CWCGB) with 600 days of curing time were studied under uniaxial loading conditions. Waste concrete particles of $5 \mathrm{~mm}$ acting as fine aggregates substituted for $30 \%$ and $50 \%$ fine coal gangue in the cemented coal gangue backfilling (CGB). AE was used to test the ring count and changing rule of the accumulated energy, locate the event for positioning, and calculate the number of events. The average ultrasonic wave velocity was measured via an ultrasonic detector. The characteristics of the microfractures were observed via a scanning electron microscope. The results showed that the specimens with $30 \%$ and $50 \%$ waste concrete replacement rates underwent ultrasonic wave velocity stabilization and a rapid decline stage under uniaxial compression; for the former case, the decline started earlier. The AE ring count attained peaks at the pore compression stage, yield stress point, stress peak value, and residual stress stage with no added waste concrete and $30 \%$ and $50 \%$ waste concrete substitution rates. The value and consequent frequency of the ringing count peak and cumulative energy slope increased with increasing waste concrete substitution rate. A microcrack was observed at the interfacial transition zone between the cement paste and gangue owing to the alkali-aggregate reaction effect. However, a better bonding performance was exhibited by the waste concrete particles and paste.

\section{Introduction}

As a major construction material, concrete is widely used owing to the rapid growth in the urbanization in China. The demolition of old constructions generates a large amount of waste concrete, which is disposed at will and leads to various environmental problems. It is reported that more than $200 \mathrm{Mt}$ of waste concrete is currently being produced each year in China [1]. Therefore, concrete recycling producing recycled aggregate concrete (RAC) to partially substitute the natural aggregates has been recognized as an effective approach to offset their shortage and for waste concrete disposal. The other effective method of using waste concrete is to use it in cemented coal gangue backfilling (CGB). It can be mixed with cement, gangue, fly ash, and other solid waste, transported through a pipeline to the goaf, and forms a filling body after solidification as "artificial rock," allowing efficient control of surface subsidence [2,3] (Figure 1). The addition of RAC to CGB not only moderately increases the filling strength but also supplements the shortage of coal gangue in some mines and reduces the material cost $[4,5]$. Because a backfilling body is directly in contact with the roof and supports the stress from the overlying rock, it is very important to monitor and evaluate its stability. The monitoring and evaluation of the mechanical property change of filling materials under uniaxial compression have been discussed. Achieving this for CGB has important practical significance $[6,7]$.

The methods for monitoring and evaluating the material stability include acoustic emission (AE) and ultrasonic 
monitoring. During uniaxial loading, a filling material can become damaged or fractured. The resulting energy is released and transmitted via the material media and reflected by the receiving AE signal. When an ultrasonic wave is transmitted through a material, the ultrasonic rate changes owing to the closure, initiation, and expansion of the cracks in the material under uniaxial compression. Therefore, AE and ultrasonic monitoring are used to monitor the occurrence of backfilling.

Many scholars have studied the ultrasonic response characteristics of rocks with different lithology, concrete, and cemented paste backfilling (CPB) during loading. Yasar and Erdogan [8] established a correlation between the ultrasonic properties and compressive strength of carbonate rocks. Ulucan et al. [9] also correlated the compressive strength of concrete with its ultrasonic pulse velocity (UPV). $\mathrm{Fu}$ and Wang [10] found from the ultrasonic nondestructive testing of a concrete component that the amplitudes of the ultrasonic parameters of the concrete component cracks were the most sensitive. When the coupling is good and test conditions are approximately the same, the amplitude value of the attenuation can be used to sharply determine the main basis of the defect in the concrete members. The velocity parameters of an ultrasonic wave are not sensitive to little defects. Zhu et al. [11] studied the changes in the ultrasonic wave velocity, amplitude, and main frequency of concrete under uniaxial loading. The test showed that the wave velocity exhibited a low sensitivity to the stress variation, and the wave speed was basically stable at approximately $70 \%$. Compared with the wave speed, the ultrasonic amplitude attenuation has a higher sensitivity for detecting cracks. Regarding CPB, Diezd'Aux [12] and Galaa et al. [13] obtained the UPV values for CPB samples with different binder dosages (3-5 wt.\%), but the correlation between the UPV results and $\mathrm{CPB}$ strength was not established. Consequently, Yilmaz et al. [14] conducted a study to take the advantage of the UPV measurement to predict the strength of CPB samples. Wu et al. [15] studied the uniaxial compressive strength of cemented waste rock filling material after different curing periods. It was found that the ultrasonic velocity increased with the fly ash and solid content, and the ultrasonic velocity and uniaxial compressive strength exhibited an obvious exponential dependence. Xu et al. [16] performed laboratory ultrasonic testing with different coal samples for different bedding directions and different lithology rocks and found that the longitudinal wave velocity increased with the finer mineral particles.

To investigate the evolution mechanism of the mechanic properties in the process of failure, researchers have performed much work on the AE characteristics using different rocks and concrete. Ji et al. [17] studied the frequency characteristics of the AE signals for granite under the condition of a single axial compression and assumed that the rate of the AE ringing gradually changed with the increase in the relative stress. Qin et al. [18] indicated that the AE properties were dependent on the uniaxial stress and failure index. The authors found that the AE events were fewer in the elastic stage, rapidly increased in the plastic stage, reached the maximum value in the post-peak stage, and subsequently reduced gradually. Ma et al. [19] analyzed the $\mathrm{AE}$ characteristics of rocks containing microcrack sand artificial cracks. The results suggested that the AE events of the rocks including microcracks mainly depended on their pores or fissure sin mineral particles and that the number of AE events was low before rock failure. Zhao et al. [20] studied the AE characteristics of Beishan granite under uniaxial and triaxial compression. Their results exhibited that the evolution of the $\mathrm{AE}$ hit counts in the uniaxial compression test were similar to those in the triaxial compression test. Li et al. [21] presented laboratory test results for the spatial and temporal evolution of the $\mathrm{AE}$ events of granite and marble specimens under uniaxial compression. The results showed that the spatial correlation length either increased or decreased depending on the combination of the stress release and stress redistribution. $\mathrm{Xu}$ et al. [22] investigated the AE properties of skarn under uniaxial compression by cyclic loading. The experimental results suggested that the AE events rapidly increased in the postpeak stage, and the produced AE events of higher energy sharply increased when the stress obviously decreased. Furthermore, the skarn still produced abundant AE events in the unloading stage, and the AE characteristics of the skarn had no Kaiser effect under cyclic loading owing to the differences in the original fissures. However, $\mathrm{Wu}$ and $\mathrm{Yu}$ [23] presented a study with inconsistent AE occurrence number and energy intensity in the process of rock failure. Guo et al. [24] applied AE and its positioning technology to synchronously monitor the variation in the strength of concrete during loading. Accordingly, the relationship between the concrete strength index and $\mathrm{AE}$ frequency characteristic parameters was analyzed. Moreover, the AE and ultrasonic waves were concurrently used to study the failure characteristics of different lithologies. Li et al. [25] studied the deformation and failure characteristics of salt rocks under triaxial compression by using ultrasonic and acoustic emission. It was found that the AE events increased sharply, vertical wave velocity was stable, and shear wave velocity declined obviously with the rapid crack growth. Li et al. [26] applied ultrasonic transmission devices and AE to study the variation in the anisotropic wave velocity and fracture with the increase in the stress for shale under triaxial loading. The ultrasonic wave velocity and AE evolution characteristics of granite under uniaxial compression were studied by Zhang et al. [27], who found that the wave velocity and wave amplitude gradually increased as the stress increased, with the lateral velocity near the closure stress attaining the peak value.

Above all, the AE, ultrasonic evolution, and propagation properties of concrete, coal, rock, and CPB under static and different compression conditions have been studied. In these investigations, the internal damage characteristics of the various materials could be revealed by using the $\mathrm{AE}$ and ultrasonic characteristics and changing rule under the different loading conditions. However, the internal structure characteristics of cemented waste concrete-coal gangue backfilling (CWCGB) are different from those of rock, concrete, and $\mathrm{CPB}$ because the coal gangue and waste concrete particles are fine aggregates. Therefore, under 


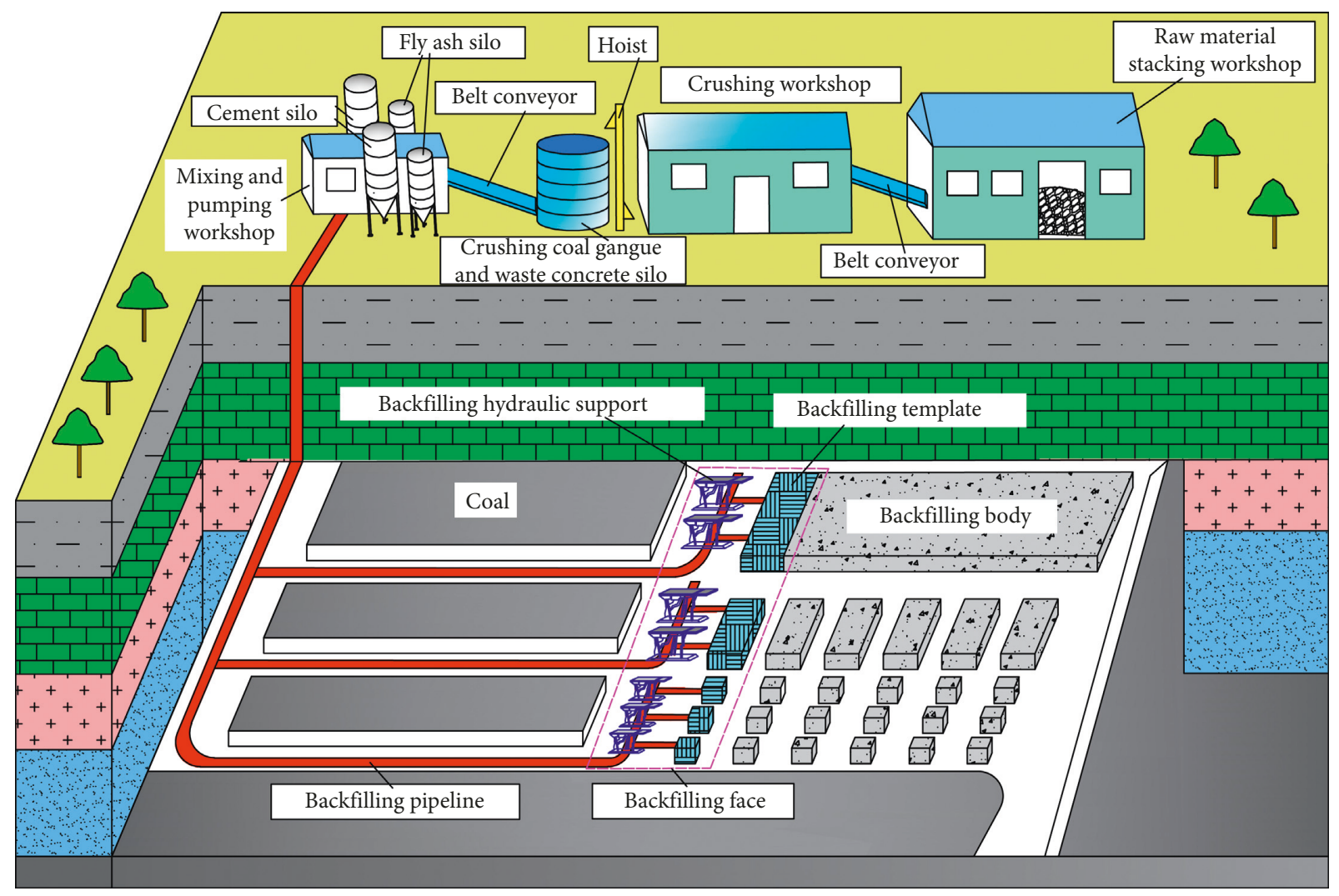

FIGURE 1: Schematic of cemented paste backfilling in a coal mine.

compression, the destruction of the features of the CWCGB would be different from the above materials. In this study, waste concrete of $-5 \mathrm{~mm}$ partly replaced the fine coal gangue within CGB, the failure mode and structural change in the CWCGB were reflected by using $\mathrm{AE}$ and performing ultrasonic testing under uniaxial loading, and the internal mechanism of the destruction was revealed by the micromorphology. It provided the experimental foundation for the obtaining the optimum ratio of CWCGB and establishing an acoustic system for evaluating the backfill body stability.

\section{Experiments}

2.1. Sample Preparation. In the test, ordinary Portland cement and fly ash are used as the cementing materials in the CWCGB. The ordinary Portland cement (grade 42.5) is obtained from Taiyuan Lion Cement, Limited by Share Ltd., and the fly ash samples (low $\mathrm{CaO}$ ) are obtained from the power plant of Xinyang Colliery. The coal gangue and waste concrete act as the aggregate in the CWCGB. Coal gangue is extracted from the gangue mountain of the Xinyang coal mine in Shanxi province, which is categorized into fine $(0-5 \mathrm{~mm})$ and coarse $(5-15 \mathrm{~mm})$ gangue according to the particle size range. The mineral composition and chemical composition of the raw materials are available in the literature [28]. The waste concrete from C30 concrete after the removal of the steel columns is put in a KET-EP $150 \times 125$ sealed jaw crusher in two crushing stages. Finally, the waste concrete particles are artificially screened by using $5 \mathrm{~mm}$ and $15 \mathrm{~mm}$ sieves. The waste concrete fine aggregates mainly contain cement mortar particles, pebble powder, sand without the mortar package, and sand particles wrapping around the mortar. Figure 2 shows the $-5 \mathrm{~mm}$ fine aggregate of coal gangue and waste concrete $(-5 \mathrm{~mm})$.

The fine aggregates of the gangue and waste concrete are screened and graded according to "the standard of sand, stone quality, and inspection method of ordinary concrete" (JGJ 52-2006). Table 1 presents the screening results of the gangue and waste concrete. It can be seen from the experimental results that cumulative residuals of the coal gangue and wasted concrete fine aggregates are very similar. What is more important is that the distribution of size of both materials allows to presume that the gaps between the aggregates will be reduced and it will increase the density of the CWCGB and enhance the compressive strength of the CWCGB [29].

The bulk density, apparent density, and water absorption of the fine and coarse aggregates are measured in accordance with "the standard of sand, stone quality, and inspection method of ordinary concrete" (JGJ 52-2006). Table 2 lists the bulk density, apparent density, and water absorption of the coal gangue and waste concrete. The value is the average values of three specimens. It can be seen that bulk density and apparent density properties are larger for the gangue than the fine waste concrete particle, and water absorption is smaller for the gangue than the fine waste concrete particle because of the higher porosity of the cement paste with the 


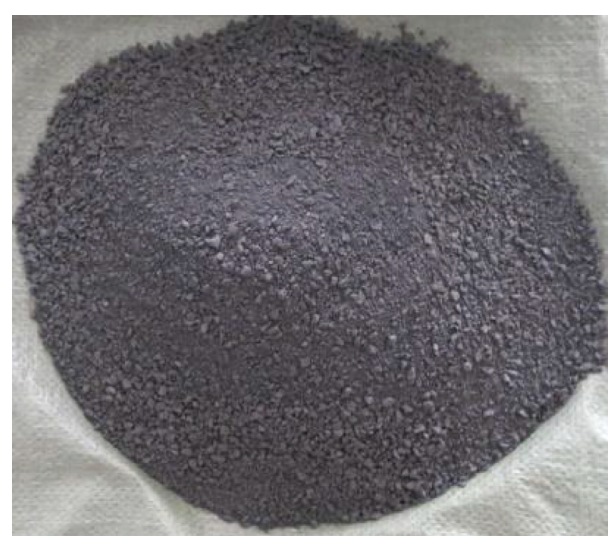

(a)

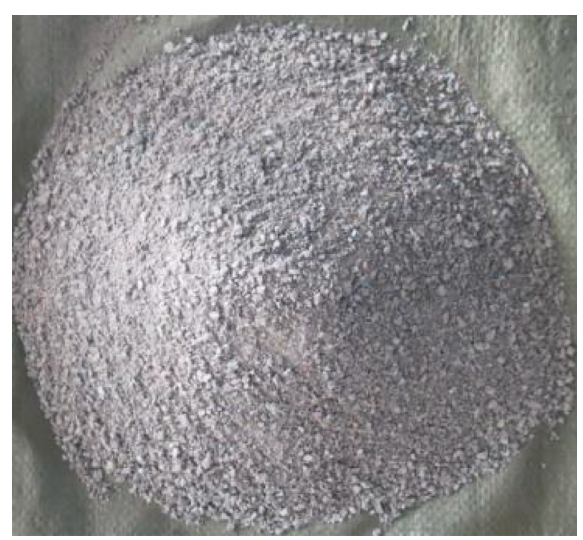

(b)

Figure 2: Coal gangue and wasted concrete fine aggregate. (a) Coal gangue. (b) Wasted concrete.

TABle 1: Cumulative residuals of the coal gangue and wasted concrete fine aggregate.

\begin{tabular}{lcccccc}
\hline \multirow{2}{*}{ Type } & \multicolumn{5}{c}{ Nominal diameter of mesh (mm) } \\
& 5 & 2.5 & 1.25 & 0.63 & 0.315 & 0.16 \\
\hline Coal gangue (\%) & 0.5 & 31.4 & 52.0 & 70.3 & 83.4 & 89.7 \\
Waste concrete (\%) & 0.4 & 31.1 & 54.2 & 73.3 & 85.7 & 91.0 \\
\hline
\end{tabular}

TABLE 2: Bulk density and apparent density of the coal gangue and waste concrete aggregate.

\begin{tabular}{lcc}
\hline Types & Fine coal gangue & Fine waste concrete \\
\hline Bulk density $\left(\mathrm{kg} \cdot \mathrm{m}^{-3}\right)$ & 1536.36 & 1295.72 \\
Apparent density & 2130.50 & 1986.70 \\
$\left(\mathrm{~kg} \cdot \mathrm{m}^{-3}\right)$ & 6.59 & 12.57 \\
\hline Absorption $(\%)$ & \\
\hline
\end{tabular}

waste concrete. Moreover, the specific surface area of the waste concrete particles is larger than of the gangue particles having the same particle size.

Based on previous experiments [28], the filling material as per the bleeding rate, slump, and strength requirement determined the proportion of the CGB to be used as the benchmark (mass ratio) as ordinary silicate cement, fly ash, coal gangue, and water ration of $1: 2: 5: 2$ (X1). The fine gangue $(-5 \mathrm{~mm})$ content accounted for $30 \%$ of the total amount of gangue with a dosage was $285 \mathrm{~kg} / \mathrm{m}^{3}$, and the medium $(5-10 \mathrm{~mm})$ and coarse $(10-15 \mathrm{~mm})$ gangue contents each accounted for $35 \%$ of the total amount of gangue, with dosages of $332.5 \mathrm{~kg} / \mathrm{m}^{3}$. The amounts of cement and fly ash were $190 \mathrm{~kg} / \mathrm{m}^{3}$ and $380 \mathrm{~kg} / \mathrm{m}^{3}$, respectively, and the mass concentration was $80 \%$. The fine waste concrete substituted the fine aggregates for the fine coal gangue (replacement rates were $30 \%(\mathrm{X} 2)$ and $50 \%(\mathrm{X} 3)$ ), as can be seen from Table 3.

After the raw materials were mixed and mechanically stirred, the slurry was transferred into $100 \mathrm{~mm} \times 100 \mathrm{~mm} \times$ $100 \mathrm{~mm}$ testing molds. After removing the template after $24 \mathrm{~h}$, the specimens were placed in a curing room (temperature: $20 \pm 2^{\circ} \mathrm{C}$; humidity: $40 \pm 5 \%$ ). In view of the long-term support of the backfill in the overburden strata, after a period of 600 days, tests for the ultrasonic variation and $\mathrm{AE}$ characteristics were conducted under uniaxial loading condition in addition to a microscopic fracture observation test.

2.2. Test Procedures and Equipment. For the test press, WAW-1000 kN microcomputer is used to control the electrohydraulic servo universal testing machine, and the loading rate is controlled by a displacement of $0.002 \mathrm{~mm} / \mathrm{s}$. For the AE test system, PCI-2 manufactured by the American Physical Acoustics Corporation (PAC) is employed, whose preamplifier is $40 \mathrm{~dB}$, threshold value is $40 \mathrm{~dB}$, resonant frequency for probing is $20-100 \mathrm{kHz}$, and sampling rate is 1 million samples per second. To conduct the ultrasonic tests, the Kang Kerui NM- $4 \mathrm{~b}$ nonmetal ultrasonic testing analyzer is selected with a sampling interval of $10 \mathrm{~s}$. As shown in Figure 3 of the stress-strainultrasonic-AE testing device, the specimen is loaded during simultaneous ultrasonic and $\mathrm{AE}$ signal collection to ensure the stress-strain-ultrasonic-AE signal numerical collection synchronization. The AE probe is coupled to the surface of the concrete and fixed with adhesive tape to ensure good reception of the signal. The micromorphology of the CWCGB is observed via a scanning electron microscope (SEM). For the observation, the surface is polished with decreasing granulation. Microstructural characterization is performed on the polished sample using a Hitachi TM-3000 SEM. Before the SEM scanning, the surfaces of the thin sections are sputter-coated with platinum $(\mathrm{Pt})$.

\section{Results and Discussion}

3.1. AE Characteristics of CWCGB. Figure 4 shows the relational graph of the CGB and CWCGB stress and AE counts under uniaxial loading. It can be seen that the peak value for specimen X1, X2, and X3 were, respectively, $8 \mathrm{MPa}, 8.5 \mathrm{MPa}$, and $9.7 \mathrm{MPa}$. The reason for this trend is that the surface of the CWCGB has small cracks between the waste concrete particles and paste. Moreover, as the surface of the waste concrete is rougher than the coal gangue, it has a larger 
TABLE 3: Mixing ratio of the CGB and CWCGB.

\begin{tabular}{|c|c|c|c|c|c|c|}
\hline Serial number & Cement & Fly ash & Coarse gangue & Fine gangue & Fine waste gangue & Water \\
\hline $\mathrm{X} 1$ & 1 & 2 & 3.5 & 1.50 & 0 & 2 \\
\hline $\mathrm{X} 2$ & 1 & 2 & 3.5 & 1.05 & 0.45 & 2 \\
\hline $\mathrm{X} 3$ & 1 & 2 & 3.5 & 0.75 & 0.75 & 2 \\
\hline
\end{tabular}

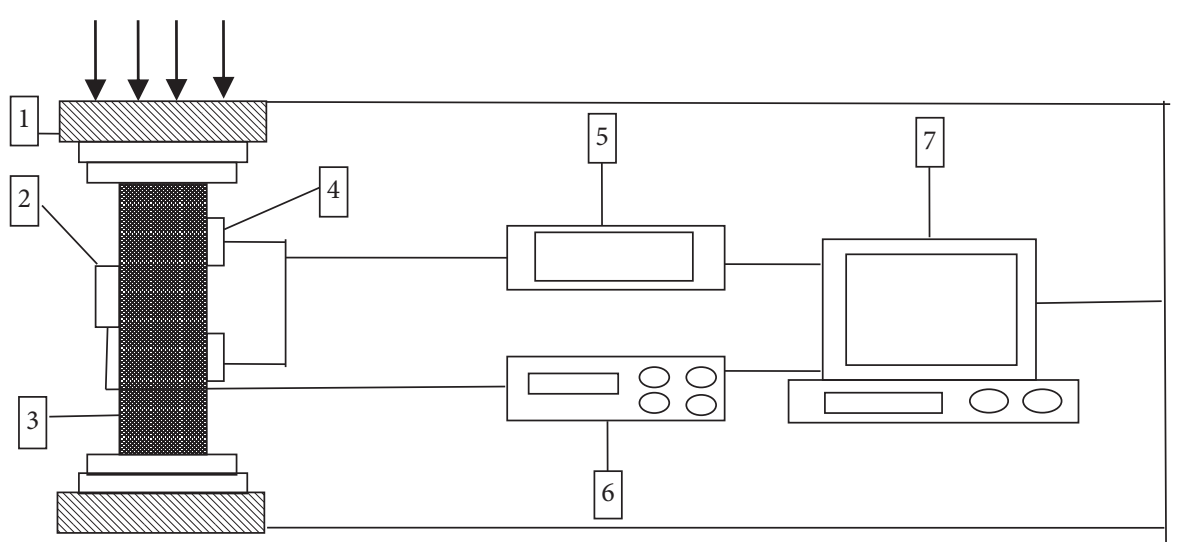

FIGURE 3: Stress-strain-ultrasonic-AE testing device diagram. 1, insulation pad; 2, ultrasonic probe; 3, specimen 4, acoustic emission probe; 5, acoustic emission detector; 6, ultrasonoscope; 7, stress control system; ultrasonic data acquisition system; stress-strain data acquisition system; AE data acquisition system.



(a)

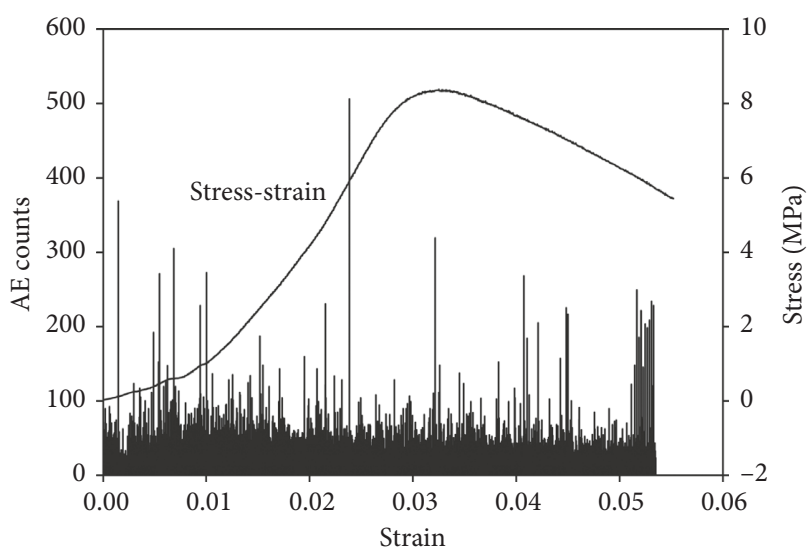

(b)

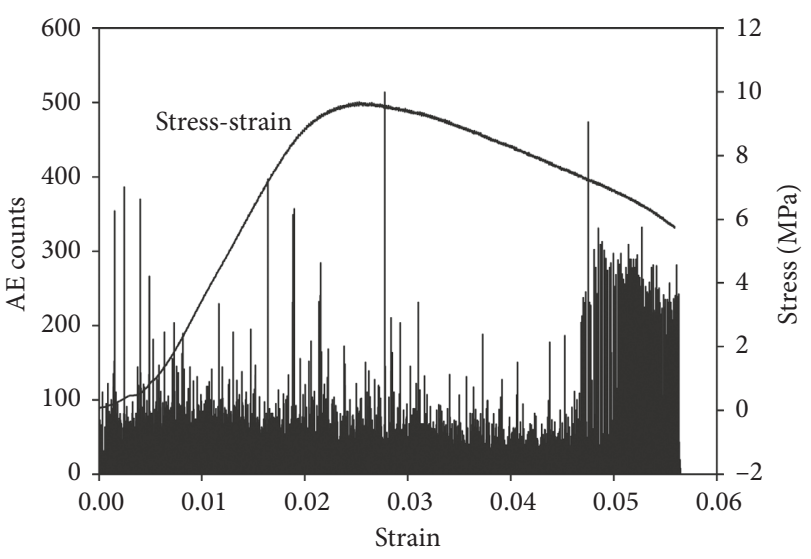

(c)

FIGURE 4: Relational graph of the CGB and CWCGB stress and AE counts. (a) No adding waste concrete. (b) $30 \%$ waste concrete substitution. (c) $50 \%$ waste concrete substitution. 
friction coefficient, which contributes to the more cementing between the aggregates and paste (seen subsequently in Figure 5) and could increase the strength of the backfilling material. It can be demonstrated that the waste concrete as supporting skeleton is more conducive for supporting the overburden load. In addition, the stress peak value with no added waste concrete and waste concrete substitution rate of $30 \%$ and $50 \%$ for $28 \mathrm{~d}$ curing time is $6.9 \mathrm{MPa}, 7.5 \mathrm{MPa}$, and 8.0 MPa, respectively. The stress peaks of CWCGB for $600 \mathrm{~d}$ is more than for $28 \mathrm{~d}$ with the same substitution of waste concrete, which due to the pozzolanic reaction after $28 \mathrm{~d}$ curing times [30].

The stress-strain curves of the CGB and CWCGB specimens under the uniaxial loading are mainly divided into four stages: pore closure stage $\left(0-\varepsilon_{\mathrm{a}}\right)$, reversible elastic deformation stage $\left(\varepsilon_{\mathrm{a}}-\varepsilon_{\mathrm{b}}\right)$, unstable fracture development stage $\left(\varepsilon_{\mathrm{b}}-\varepsilon_{\mathrm{c}}\right)$, and residual deformation stage $\left(\varepsilon_{\mathrm{c}}-\varepsilon_{\mathrm{d}}\right)$ (Figure 6).

3.1.1. Pore Closure Stage $\left(0-\varepsilon_{\mathrm{a}}\right)$. The compaction and consolidation of the pores and microcracks occur in this case. The peak frequency of the ringing count appears to be low for the no added waste concrete, and its value is also decreased compared with the added waste concrete cases. The peak frequency and value of the ringing count are increased with the increasing substitution rate for the waste concrete. In this stage, the weak signals of the AE mainly come from the tiny crack and pore closure surface contact slip. This is because the larger specific surface area and rougher surface of the waste concrete than of the gangue produce more energy in the process of contact friction.

3.1.2. Elastic Deformation Stage $\left(\varepsilon_{\mathrm{a}}-\varepsilon_{\mathrm{b}}\right)$. Peaks in the ring counts are rarely found for the specimens with different waste concrete contents, indicating that the microfissuring would be relatively stable in these specimens.

\subsubsection{Plastic Deformation to Unstable Fracture Development} $\left(\varepsilon_{\mathrm{b}}-\varepsilon_{\mathrm{c}}\right)$. During the stress yield phase, there is a significant peak in the ringing count, indicating that the microcrack in the filling material has expanded. With the increasing waste concrete content, the ring count peak intensity and frequency increase during the yield point stress and peak strength stage caused by the crack cut-through between the paste and waste concrete and between the paste and gangue. When the stress reaches the peak, the intensity of the ring count also attains the peak, and the ring count peak appears to lag for the all specimens corresponding to the stress peak, which can be attributed to the crack cut-through and the detached bulk generating a wide-range violent gliding along the plane of the fracture.

3.1.4. Residual Deformation Stage $\left(\varepsilon_{\mathrm{c}}-\varepsilon_{\mathrm{d}}\right)$. The frequency of the ring count attains a peak for the different waste concrete contents; however, the specimens lose their support ability, the AE energy source from the broken blocks of the stripping off between the particles, and the friction. With the increase in the waste concrete substitution rate, the peak value of the ringing count increases.

It can be seen from Figure 7 that, for the no added waste concrete and $30 \%$ and $50 \%$ waste concrete substitution for the fine coal gangue, the accumulation of energy change rate of the filling material increases. This reflects that the more waste concrete content of the filling material can release more energy in the process of uniaxial loading, which in turn can be attributed to the more energy produced by the friction between the particles of the gangue and waste concrete. More energy is released by the removal of the cement interfacial transition zone (ITZ) between the paste and aggregates with the increasing waste concrete content in the process of the breeding, resulting in the occurrence and extension of the crack. The reasons for this are the larger specific surface area and the more interfacial roughness of waste concrete particles leading to the more bond strength $[31,32]$.

Figures 8 and 9 show the characteristics of the external failure with $30 \%$ and $50 \%$ waste concrete substitution under uniaxial loading, respectively. Figures 10 and 11 show the characteristics of the $\mathrm{AE}$ events with $30 \%$ and $50 \%$ waste concrete substitution under uniaxial loading, respectively. At the stage of pore compaction $\left(0-\sigma_{\mathrm{a}}\right)$, there is no obvious crack in the specimen surface (Figures 8(a) and 9(a)). The number of AE events for the $50 \%$ waste concrete substitution rate is more than for the $30 \%$ waste concrete substitution rate (Figures $10(\mathrm{a})$ and $11(\mathrm{a})$ ). This can be attributed to the higher fine content of the coal gangue and more number of microcracks in the void and microcrack compaction stage (as shown subsequently in Figure 5).

In the elastic phase $\left(\sigma_{\mathrm{a}}-\sigma_{\mathrm{b}}\right)$, the number of AE events for the CWCGB with $30 \%$ waste concrete substitution rate is more than $50 \%$ substitution rate (Figures 10 (b) and $11(\mathrm{~b})$ ), which is related to the weak ITZ between the gangue and paste that is more likely to produce cracks in the process of continuous pressure. However, few microcracks would be seen on the surface of the specimen (Figures 8(b) and 9(b)).

In the unstable fracture development stage $\left(\sigma_{\mathrm{b}}-\sigma_{\mathrm{c}}\right)$, corresponding to the transition from the yield stage to the stress peak stage, there are obvious cracks undergoing expansion. There are two distinct main vertical fractures at the sides of the specimen that extend rapidly from the top to the bottom. Furthermore, between the two main fissures, a secondary fissure develops continuously, such that they penetrate each other and go through the main crack. However, the secondary fissure between the main microcracks has a less distribution for the $50 \%$ substitution rate (Figures 8(c), 8(d), 9(c), and 9(d)).

In the residual deformation stage $\left(\sigma_{\mathrm{c}}-\sigma_{\mathrm{d}}\right)$, the extent degree of the main crack and secondary fissure increases, and the debris of the CWCGB specimen falls continuously in the process of compression (from Figures 8(e), 8(f), 9(e), and $9(\mathrm{f})$ ). The number of AE events for the $50 \%$ substitution rate is more than that for the $30 \%$ substitution rate (Figures 10(c) and 11(c)). This can be attributed to the larger specific surface area of the waste concrete producing more ITZ cracks and to the more power to overcome the cementing ability between the waste concrete and paste. 



Figure 5: SEM photos of the CGB sample under axial compression.

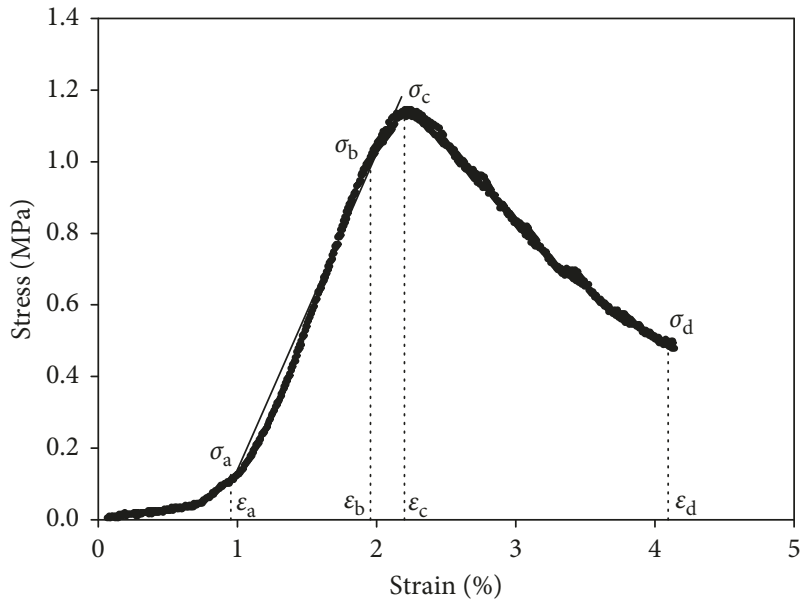

Figure 6: Stress-strain curve of CGB.

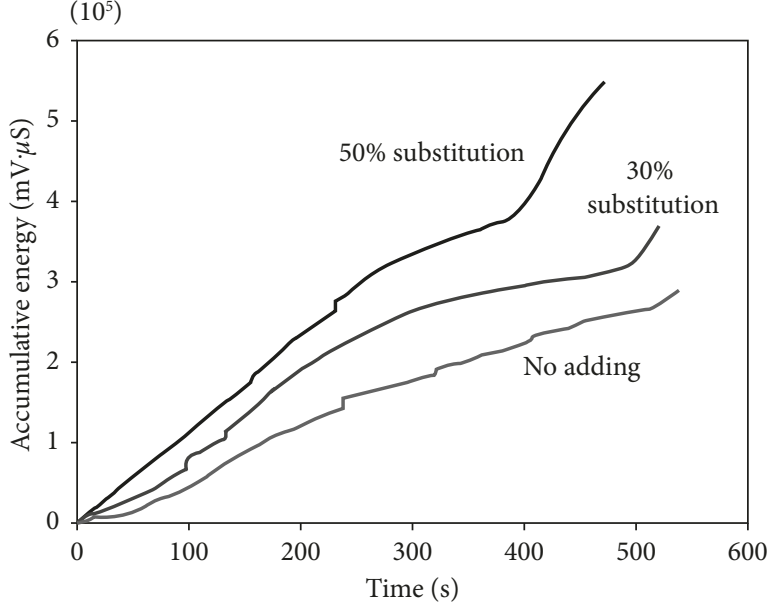

Figure 7: Relationship between the accumulative energy and loading time with different waste concrete substitutions. 


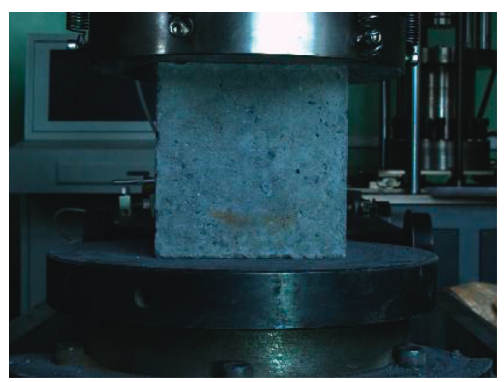

(a)

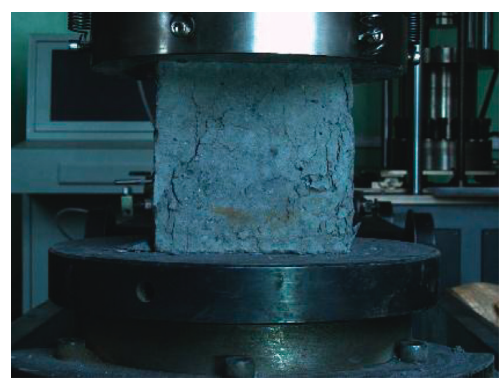

(d)

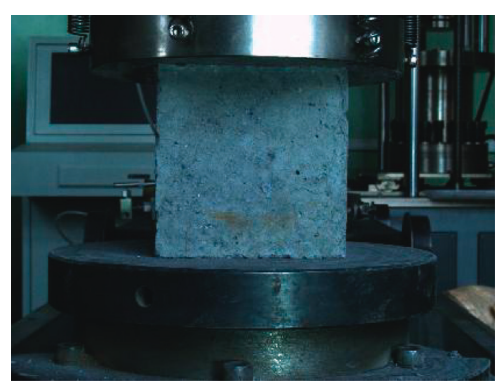

(b)

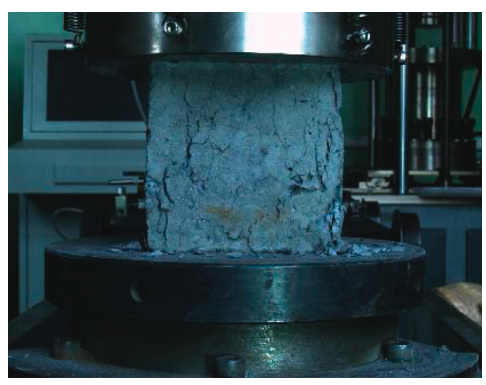

(e)

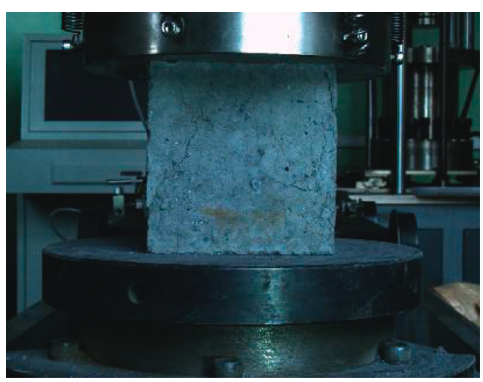

(c)



(f)

FiguRE 8: Characteristics of the external failure with $30 \%$ waste concrete substitution under uniaxial loading. (a-f) correspond to $0-\sigma_{\mathrm{a}}, \sigma_{\mathrm{a}}-\sigma_{\mathrm{b}}$, $\sigma_{\mathrm{b}}-\sigma_{\mathrm{c}}, \sigma_{\mathrm{b}}-\sigma_{\mathrm{c}}, \sigma_{\mathrm{c}^{-}} \sigma_{\mathrm{d}}$, and $\sigma_{\mathrm{c}^{-}} \sigma_{\mathrm{d}}$ of the stress stage in Figure 6.

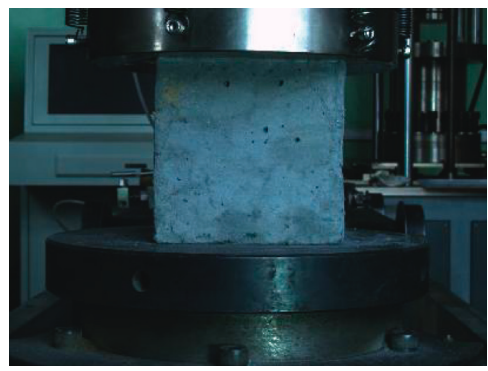

(a)

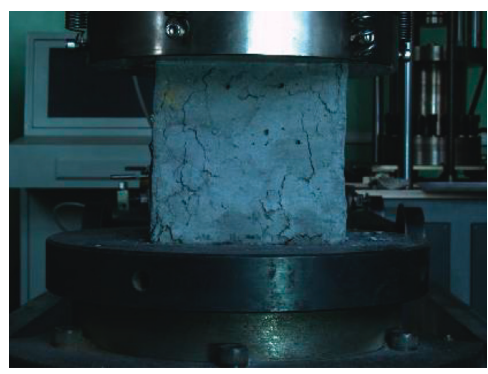

(d)

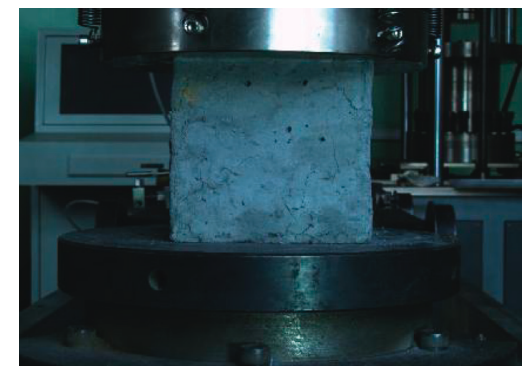

(b)

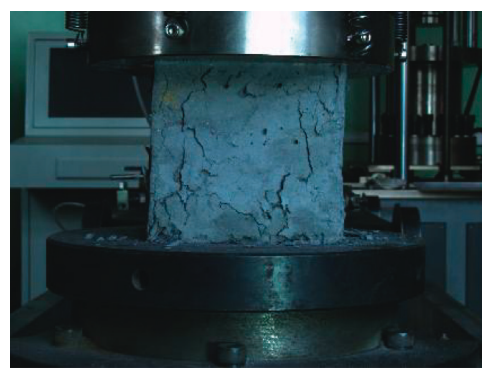

(e)

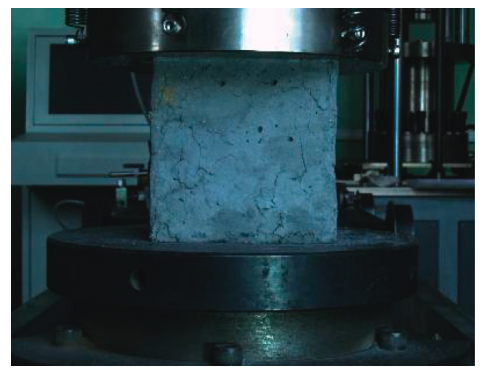

(c)

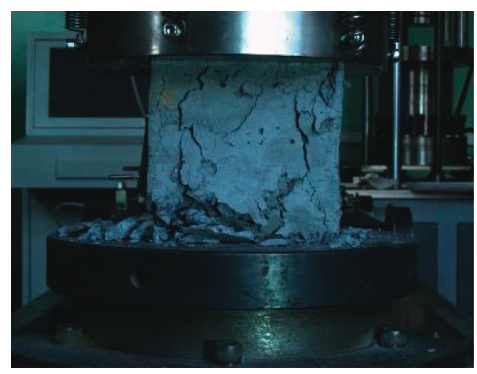

(f)

FIGURE 9: Characteristics of the external failure with $50 \%$ waste concrete substitution under uniaxial loading. (a-f) correspond to $0-\sigma_{\mathrm{a}}, \sigma_{\mathrm{a}}-\sigma_{\mathrm{b}}$, $\sigma_{\mathrm{b}}-\sigma_{\mathrm{c}}, \sigma_{\mathrm{b}}-\sigma_{\mathrm{c}}, \sigma_{\mathrm{c}^{-}}-\sigma_{\mathrm{d}}$, and $\sigma_{\mathrm{c}^{-}} \sigma_{\mathrm{d}}$ of the stress stage in Figure 6 .

3.2. Ultrasonic Characteristics of CWCGB. The CWCGB contains solid, liquid, and gas phase media. The solid-state mainly includes the waste concrete, coal gangue, and paste; the liquid exists in the moisture inside the material porosity; and the gas mainly exists in the pore and microcracks. When the curing time is 600 days, there is hardly any water in the material because it evaporates or is involved in the hydration reaction.
The propagation of ultrasonic waves in the CWCGB specimen is primarily through the solid and gas-phase media. The propagation velocity in the different media in the CWCGB specimen is different, and it can be refracted, diffracted, or absorbed by the cracks in the CWCGB specimen, so that the propagation speed is reduced. The change in the ultrasonic wave velocity reflects the 


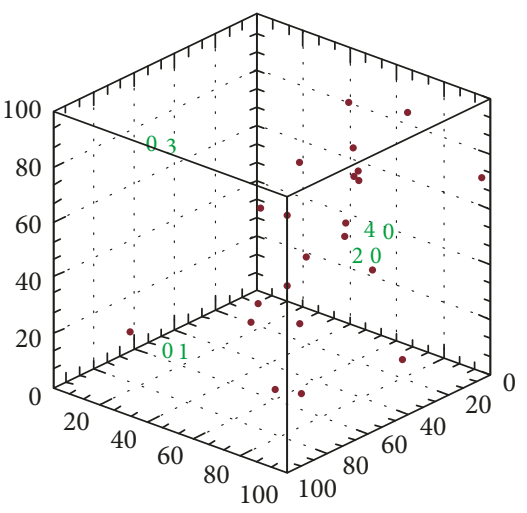

(a)

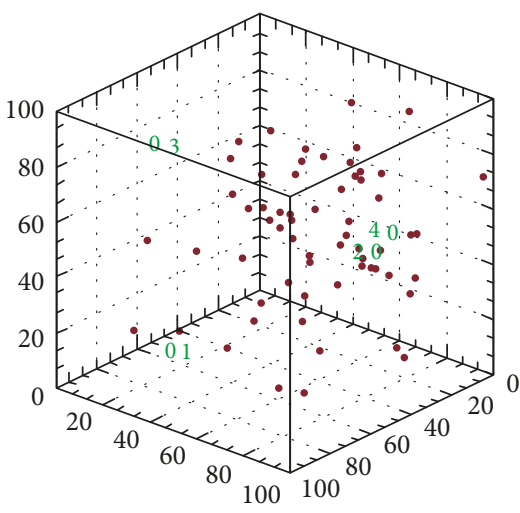

(b)

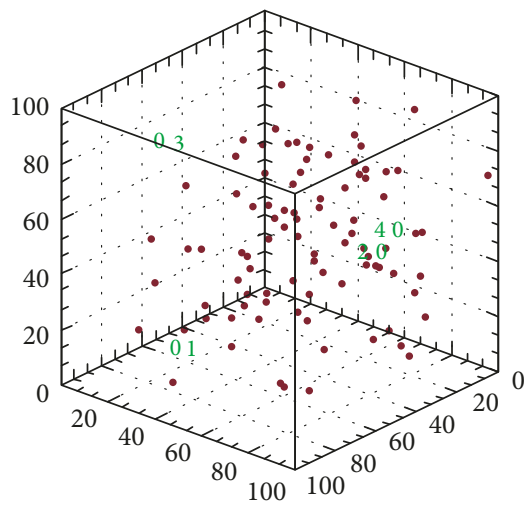

(c)

FIGURE 10: Characteristics of the AE events with $30 \%$ waste concrete substitution under uniaxial loading. (a-c) correspond to $0-\sigma_{\mathrm{a}}, \sigma_{\mathrm{a}}-\sigma_{\mathrm{b}}$, and $\sigma_{\mathrm{c}^{-}} \sigma_{\mathrm{d}}$ of the stress stage in Figure 6.

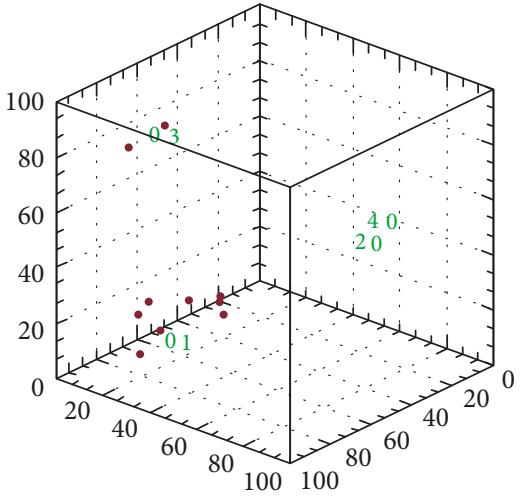

(a)

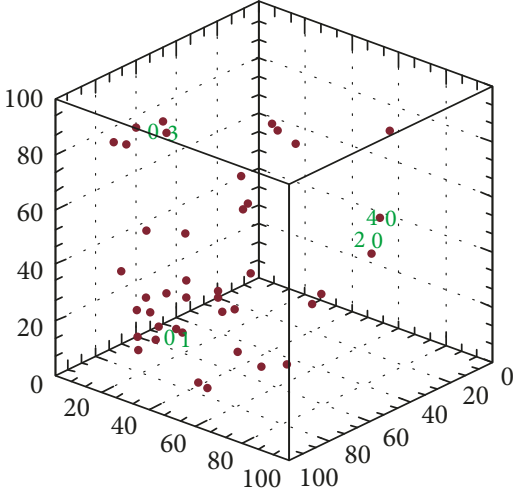

(b)

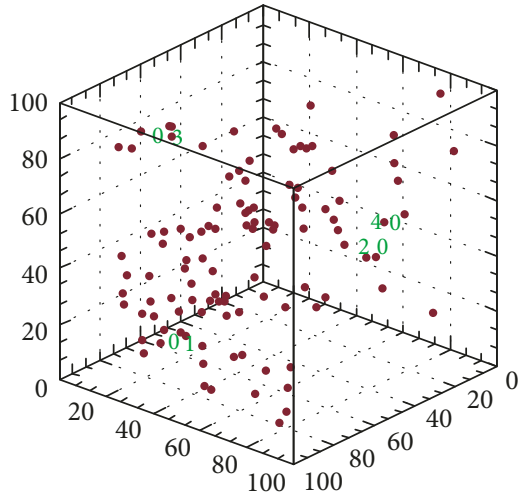

(c)

Figure 11: Characteristics of the AE events with $50 \%$ waste concrete substitution under uniaxial loading. (a-c) correspond to $0-\sigma_{\mathrm{a}}, \sigma_{\mathrm{a}}-\sigma_{\mathrm{b}}$, and $\sigma_{\mathrm{c}^{-}} \sigma_{\mathrm{d}}$ of the stress stage in Figure 6.

development and extent of the fracture in the CWCGB specimen under uniaxial compression.

It can be seen from Figure 12, at initial point (1), for the waste concrete substitution rate of $30 \%$ (Figure 12(a)) and $50 \%$ (Figure 12(b)), the average ultrasonic wave velocity is approximately $2.3 \mathrm{~km} / \mathrm{s}$ and $2.05 \mathrm{~km} / \mathrm{s}$, respectively. This can be attributed to the more number of voids and cracks in the waste concrete and its higher bulk density and apparent density than the gangue. Thus, the propagation velocity of the ultrasound through the gangue medium is higher than the waste concrete medium transmission rate. At point (2), the ultrasonic wave velocity obviously increases for the two waste concrete contents at the beginning of pressure, which can be related to the compaction of the voids and microcracks in the material. In the process of continuous pressure application, the wave velocity is in a relatively flat stage.

In region (3), corresponding to the later period of the pore compaction stage and early period of the elastic stage, the ultrasonic velocity fluctuates associated with the closing of the fracture and pore surface contact slip faulting. Moreover, it can be used as an indicator of the filling material entering the elastic deformation stage. After the fluctuation of the ultrasonic wave velocity, it rapidly decreases for the $30 \%$ replacement rate of the waste concrete, indicating that there are obvious cracks in the material. After region (3), the ultrasonic velocity change is very small for the $50 \%$ waste concrete substitution rate, which can be attributed to the stable performance of the CWCGB because of no obvious crack and a medium density change. Thus, the $50 \%$ waste concrete can form a relatively stable supporting system.

As the stress attains the yield point, the ultrasonic velocity exhibits a large discrepancy, as can be seen in region (4). The reason for this is that after the stress reaches the yield point, the material interior undergoes an obvious damage and is accompanied by the generation of a crack, reducing the propagation velocity of the ultrasound in the specimen. The stability of the filling body can be predicted effectively by using the ultrasonic monitoring device. At the corresponding stress peak, the ultrasonic wave velocity shows the lowest value. At this time, the damage degree of the filling material reaches the maximum and crack expansion is relatively developed. 


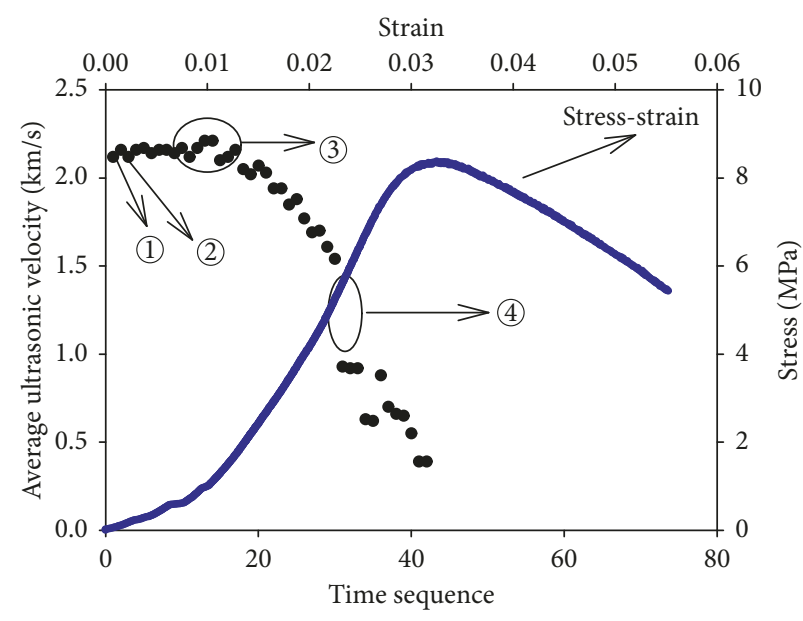

(a)



(b)

FIgURE 12: Variation in the average ultrasonic velocity with $30 \%$ (a) and 50\% (b) waste concrete substitution under uniaxial loading.

3.3. Micromorphology of CWCGB. As can be seen from the microscopic image (Figure 5), there are numerous tiny fractures in the ITZ between the coal gangue and paste in the static condition. The reason for this is that the mechanically crushed coal gangue has pozzolanic activity, and it reacts with $\mathrm{Ca}(\mathrm{OH})_{2}$ produced by the hydration of cement as an alkali-aggregate reaction at the $600 \mathrm{~d}$ curing time $[33,34]$. This is also responsible for the low strength of the CGB. Moreover, the waste concrete contains granite, which has a good contact with the paste. It can be seen that adding waste concrete as an aggregate can reduce the occurrence of the alkali-aggregate reaction and effectively increase the strength of the CGB $[35,36]$. In addition, the crack appears not only mainly on the ITZ between the coal gangue and paste but also between the waste concrete and paste under the axial loading, so that the degree of the expansion crack between the coal gangue and paste is more.

\section{Conclusion}

(1) The AE ring count peak appears at the pore compression stage, yield stress point, stress peak, and residual stress stage with different waste concrete contents under uniaxial loading. The peak value and frequency of the $\mathrm{AE}$ ring counts increase with the increasing waste concrete substitute rate, and the slope of the accumulative energy curve gradually increases with the increasing waste concrete substitution rate.

(2) The ultrasonic wave velocity for the $30 \%$ waste concrete substitution rate is higher than for the $50 \%$ waste concrete substitution rate under the unloading condition. The ultrasonic wave velocity fluctuates at the elastic deformation stage. With continuous loading, the wave velocity of the $30 \%$ waste concrete substitution rate drops rapidly, whereas for the $50 \%$ substitution rate, it is relatively stable. The least ultrasonic wave velocity values for the two waste concrete substitution rates of the CWCGB are different.

(3) During the pore compaction stage, there is no obvious crack on the specimen surface. The number of acoustic emission events for the $30 \%$ waste concrete rate is more than for the $50 \%$ waste concrete substitution. At the elastic stage, the specimen is compressed and deformed, and there is a microcrack on the specimen surface. There is less distribution of the secondary fissures between the two ends of the surface of the filling material of the abandoned concrete and the main fractures extend along the axial direction. From the yield to the stress peak phase, there is an obvious crack generation; there are two main fractures stretching along the axis direction, and the secondary interstice between the main cracks develops continuously. In the residual deformation stage, the $\mathrm{AE}$ events of the $50 \%$ waste concrete substitution are more than for the 30\% substitution. After the stress peak, the expanding degree of the main crack and secondary fissure increases continuously, and the debris of the CWCGB keeps falling. It can be seen from the microscopic observation that there are obvious cracks at the interfacial transition zone between the gangue and paste, and the cementation properties of the waste concrete particles and paste are better. There are obvious cracks in both interfacial transition zones under uniaxial compression. In our study, only $100 \mathrm{~mm} \times 100 \mathrm{~mm} \times 100 \mathrm{~mm}$ size specimen of CWCGB were used to test $\mathrm{AE}$ and ultrasonic characteristics, and these characteristics of CWCGB with different size specimen should be investigated. Moreover, the comparison of the results from the field to this experimental conclusion should be presented in the next. 


\section{Data Availability}

The data used to support the findings of this study are included within the article.

\section{Conflicts of Interest}

The authors declared no potential conflicts of interest with respect to the research, authorship, and/or publication of this article.

\section{Acknowledgments}

This work was supported by the Joint Research Fund under cooperative agreement between NSFC and Funds for CoalBased Low-Carbon Technology of Shanxi (No. U1710258), the National Natural Science Foundation of China (Nos. 51574172 and 51804208), the Research Fund of the State Key Laboratory of Coal Resources and Safe Mining, CUMT (SKLCRSM18KF016), and China Postdoctoral Science Foundation (2018M632423).

\section{References}

[1] J. Z. Xiao, W. G. Li, and C. S. Poon, "Recent studies on mechanical properties of recycled aggregate concrete in China-a review," Science China Technological Sciences, vol. 55, no. 6, pp. 1463-1480, 2012.

[2] G. R. Feng, X. Q. Jia, Y. X. Guo et al., "Influence of the wasted concrete coarse aggregate on the performance of cemented paste backfill," Journal of China Coal Society, vol. 40, no. 6, pp. 1320-1325, 2015.

[3] G. R. Feng, X. Q. Jia, Y. X. Guo et al., "Study on mixture ratio of gangue-waste concrete cemented paste backfill," Journal of Mining and Safety Engineering, vol. 32, no. 6, pp. 1072-1079, 2016.

[4] M. G. Qian, X. X. Miao, and J. L. Xu, "Green mining of coal resources harmonizing with environment," Journal of China Coal Society, vol. 32, no. 1, pp. 1-7, 2007.

[5] T. Qi, G. Feng, Y. Li, Y. Guo, J. Guo, and Y. Zhang, "Effects of fine gangue on strength, resistivity, and microscopic properties of cemented coal gangue backfill for coal mining," Shock and Vibration, vol. 2015, Article ID 752678, 11 pages, 2015.

[6] M. Fall and M. Pokharel, "Coupled effects of sulphate and temperature on the strength development of cemented tailings backfills: portland cement-paste backfill," Cement and Concrete Composites, vol. 32, no. 10, pp. 819-828, 2010.

[7] M. Fall and S. S. Samb, "Effect of high temperature on strength and microstructural properties of cemented paste backfill," Fire Safety Journal, vol. 44, no. 4, pp. 642-651, 2009.

[8] E. Yasar and Y. Erdogan, "Correlating sound velocity with the density, compressive strength and Young's modulus of carbonate rocks," International Journal of Rock Mechanics and Mining Sciences, vol. 41, no. 5, pp. 871-875, 2004.

[9] Z. C. Ulucan, K. Turk, and M. Karatas, "Effect of mineral admixtures on the correlation between ultrasonic velocity and compressive strength for self-compacting concrete," Russian Journal of Nondestructive Testing, vol. 44, no. 5, pp. 367-374, 2008.

[10] Z. W. Fu and X. Wang, "A study of ultrasonic nondestructive testing detecting the defects of concrete components," Rock and Soil Mechanics, vol. 28, pp. 783-788, 2007.
[11] J. Y. Zhu, L. Z. Chen, and X. S. Yan, "Ultrasonic pulses behavior in concrete during compressive loading," Engineering Mechanics, vol. 15, no. 3, pp. 11-117, 1998.

[12] M. Diezd'Aux, Ultrasonic Wave Measurement through Cemented Paste Backfill, University of Toronto, Toronto, ON, Canada, 2008.

[13] A. M. Galaa, B. D. Thompson, M. W. Grabinsky, and W. F. Bawden, "Characterizing stiffness development in hydrating mine backfill using ultrasonic wave measurements," Canadian Geotechnical Journal, vol. 48, no. 8, pp. 1174-1187, 2011.

[14] T. Yilmaz, B. Ercikdi, K. Karaman, and G. Külekci, "Assessment of strength properties of cemented paste backfill by ultrasonic pulse velocity test," Ultrasonics, vol. 54, no. 5, pp. 1386-1394, 2014.

[15] D. Wu, Y. L. Zhang, and Y. C. Liu, "Mechanical performance and ultrasonic properties of cemented gangue backfill with admixture of fly ash," Ultrasonics, vol. 64, pp. 89-96, 2016.

[16] X. L. Xu, R. Zhang, F. Dai, B. Yu, M. Z. Gao, and Y. F. Zhang, "Effect of coal and rock characteristics on ultrasonic velocity," Journal of China Coal Society, vol. 40, no. 4, pp. 793-800, 2015.

[17] H. G. Ji, H. W. Wang, and S. Z. Cao, "Experimental research on frequency characteristics of acoustic emission signals under uniaxial compression of granite," Chinese Journal of Rock Mechanics and Engineering, vol. 31, no. S1, pp. 29002905, 2012.

[18] S. Q. Qin, Z. D. Li, and Y. M. Lin, "Micro process of rock fracture and acoustic emission," Journal of Northeast University of Technology, vol. 12, no. 3, pp. 247-253, 1991.

[19] S. L. Ma, X. L. Lei, and L. Q. Liu, "Effects of heterogeneity in rock samples on spatial land temporal distribution of acoustic emission and their significance in seismology," Chinese Journal of Geophysics, vol. 47, no. 1, pp. 127-131, 2004.

[20] X. G. Zhao, M. Cai, J. Wang, and L. K. Ma, "Damage stress and acoustic emission characteristics of the Beishan granite," International Journal of Rock Mechanics and Mining Sciences, vol. 64, pp. 258-269, 2013.

[21] Y. H. Li, J. P. Liu, X. D. Zhao, and Y. J. Yang, "Experimental studies of the change of spatial correlation length of acoustic emission events during rock fracture process," International Journal of Rock Mechanics and Mining Sciences, vol. 47, no. 8, pp. 1254-1262, 2010.

[22] S. C. Xu, X. T. Feng, and B. R. Chen, "Experimental study of skarn under uniaxial cyclic loading and unloading test and acoustic emission characteristics," Rock and Soil Mechanics, vol. 30, no. 10, pp. 2929-2934, 2009.

[23] Y. S. Wu and X. B. Yu, "Experimental study on the acoustic emissions characteristics of rock sat uniaxial compression," Metal Mine, vol. 10, pp. 25-28, 2008.

[24] Q. H. Guo, B. P. Xi, and Z. W. Li, "Experimental research on relationship between frequency characteristics of acoustic emission and strength parameter in concrete," Journal of Central South University (Science and Technology), vol. 46, no. 4, pp. 1482-1488, 2015.

[25] H. R. Li, C. H. Yang, W. G. Zhao, B. Liu, and X. Y. Yin, "Experimental studies of failure characteristics and evolution laws of ultrasonic velocity and acoustic emission for salt rock under triaxial loading," Rock and Soil Mechanics, vol. 37, no. 9, pp. 2458-2476, 2016.

[26] X. Y. Li, X. L. Lei, Q. Li, and X. C. Li, "Experimental investigation of Sinian shale rock under triaxial stress monitored by ultrasonic transmission and acoustic emission," Journal of Natural Gas Science and Engineering, vol. 43, pp. 110-123, 2017. 
[27] G. K. Zhang, H. B. Li, X. Xia, Q. Y. Chen, J. S. Liu, and Z. H. Huang, "Experiment study on acoustic emission and wave propagation in granite under uniaxial compression," Chinese Journal of Rock Mechanics and Engineering, vol. 36, no. 5, pp. 1133-1144, 2017.

[28] T. Y. Qi, G. R. Feng, Y. X. Guo et al., "Experimental study on the changes of coal paste backfilling material performance during hydration process," Journal of Mining and Safety Engineering, vol. 32, no. 1, pp. 42-48, 2015.

[29] L. G. Li, C. J. Lin, G. M. Chen, A. K. H. Kwan, and T. Jiang, "Effects of packing on compressive behaviour of recycled aggregate concrete," Construction and Building Materials, vol. 157, pp. 757-777, 2017.

[30] X. Q. Jia and G. R. Feng, "Influence of fine aggregate from waste concrete on the performances of backfill paste," Mining Research and Development, vol. 35, no. 11, pp. 39-40, 2015.

[31] Y. He, X. Zhang, Y. J. Zhang, and Y. Zhou, "Effects of particle characteristics of lightweight aggregate on mechanical properties of lightweight aggregate concrete," Construction and Building Materials, vol. 72, pp. 270-282, 2014.

[32] B. A. Tayeh, B. H. A. Bakar, M. A. M. Johari, and M. M. Ratnam, "The relationship between substrate roughness parameters and bond strength of ultra high performance fiber concrete," Journal of Adhesion Science and Technology, vol. 27, no. 16, pp. 1790-1810, 2013.

[33] C. Alexandridou, G. N. Angelopoulos, and F. A. Coutelieris, "Mechanical and durability performance of concrete produced with recycled aggregates from Greek construction and demolition waste plants," Journal of Cleaner Production, vol. 176, pp. 745-757, 2018.

[34] K. L. Lin, C. L. Hwang, J. L. Shie, Y. M. Chang, and A. Cheng, "Hydration characteristics of waste catalysts used as pozzolanic materials," Environmental Progress \& Sustainable Energy, vol. 33, no. 2, pp. 353-358, 2014.

[35] R. Kurda, J. de Brito, and J. D. Silvestre, "Indirect evaluation of the compressive strength of recycled aggregate concrete with high fly ash ratios," Magazine of Concrete Research, vol. 70, no. 4, pp. 204-216, 2018.

[36] R. Kurad, J. D. Silvestre, J. de Brito, and H. Ahmed, "Effect of incorporation of high volume of recycled concrete aggregates and fly ash on the strength and global warming potential of concrete," Journal of Cleaner Production, vol. 166, pp. 485$502,2017$. 


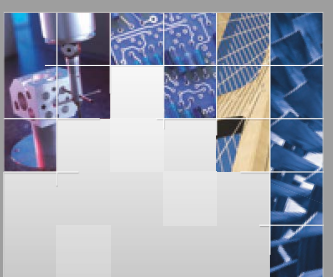

\section{Enfincering}
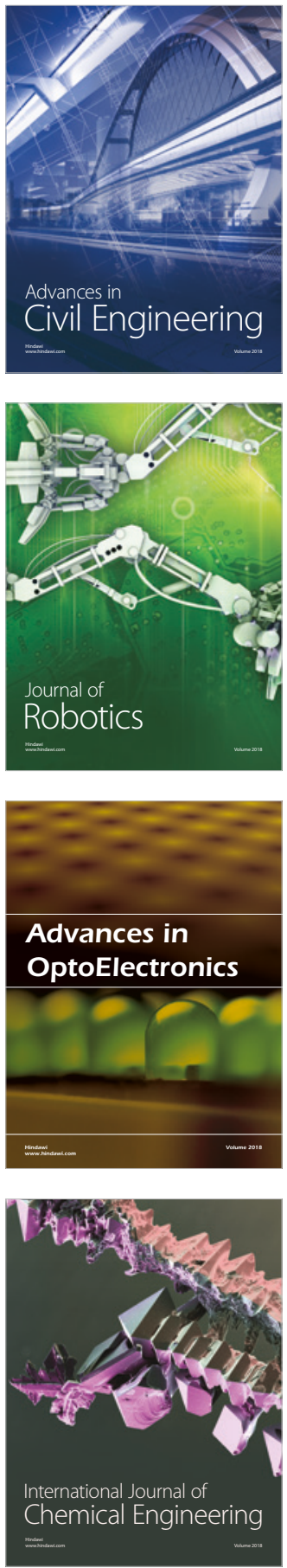

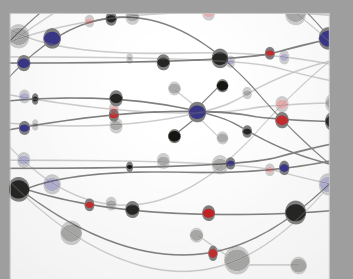

\section{Rotating \\ Machinery}

The Scientific World Journal

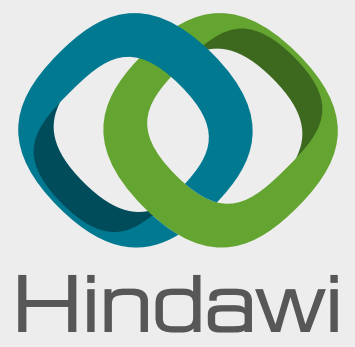

Submit your manuscripts at

www.hindawi.com



\section{Advances \\ Multimedia}
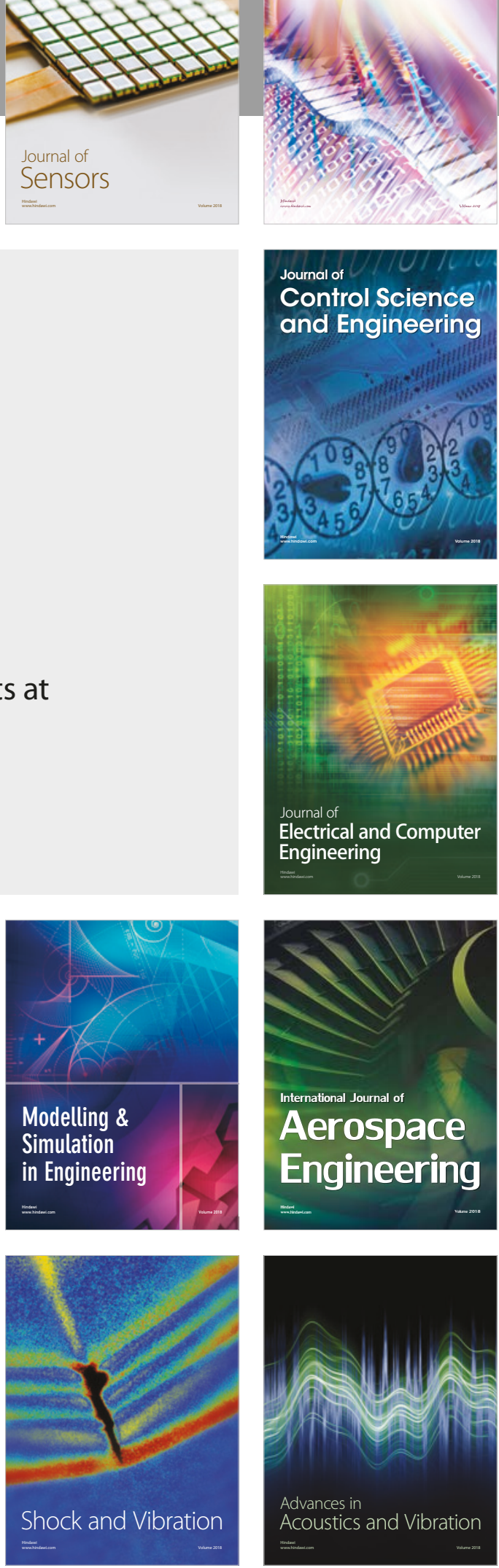